Original Research

\title{
Ecologically Friendly, Slow-Release Granular Fertilizers with Phosphogypsum
}

\author{
Kurmanbek Zhantasov ${ }^{1 *}$, Aitzhan Ziyat ${ }^{1}$, Nursulu Sarypbekova ${ }^{2}$, \\ Kamilya Kirgizbayeva ${ }^{3}$, Gani Iztleuov ${ }^{4}$, Manap Zhantasov ${ }^{5}$, \\ Guzaliya Sagitova $^{6}$, Ayganym Aryn ${ }^{1}$
}

${ }^{1}$ Department of Chemical Technology of Inorganic Substances, M. Auezov South Kazakhstan University, Shymkent, Kazakhstan

${ }^{2}$ Department of Chemistry and Chemical Technology, M. Auezov South Kazakhstan University, Shymkent, Kazakhstan

${ }^{3}$ Department of Standardization, Certification and Metrology, L.N. Gumilyov Eurasian National University, Nur-Sultan, Kazakhstan

${ }^{4}$ Department of Ecology, M. Auezov South Kazakhstan University, Shymkent, Kazakhstan

${ }^{5}$ Department of Oil and Gas Business, M. Auezov South Kazakhstan University, Shymkent, Kazakhstan

${ }^{6}$ Department of Refining and Petrochemicals, M. Auezov South Kazakhstan University, Shymkent, Kazakhstan

Received: 15 July 2021

Accepted: 20 November 2021

\begin{abstract}
The paper provides information about phosphogypsum waste from various enterprises and how it can be used in the production of slow-release fertilizer mixtures. Such fertilizer mixes can potentially be used with different types of soil, including acidified soils. Experiments were conducted on phosphogypsum samples from the old and new dumpsites under the Taraz branch of Kazphosphate LLP. All representative samples underwent chemical, mineralogical, thermal gravimetric and differential thermal analyses, as well as Fourier-Transform Infrared (FTIR) spectroscopy and polarized optical microscopy (POM). No significant differences were found in the content of the samples. Phosphogypsum from the old dumpsite contained $87.93 \%$ gypsum $\left(\mathrm{CaSO}_{4} \cdot 2 \mathrm{H}_{2} \mathrm{O}\right), 9.10 \%$ quartz $(\mathrm{SiO} 2), 17.55 \%$ calcium $(\mathrm{Ca}), 0.13 \%$ potassium $(\mathrm{K}), 0.35 \%$ phosphorus $(\mathrm{P})$, and $0.80 \%$ phosphorus pentoxide (P2O5). Phosphogypsum from the new dumpsite contained $85.04 \%$ gypsum, $10.58 \%$ quartz ( $\mathrm{SiO} 2), 19.42 \%$ calcium $(\mathrm{Ca}), 0.14 \%$ potassium $(\mathrm{K}), 0.30 \%$ phosphorus $(\mathrm{P})$, and $0.69 \%$ phosphorus pentoxide (P2O5). The current paper also offers a technological scheme for making a slow-release fertilizer mixture with phosphogypsum.
\end{abstract}

Keywords: differential thermal analysis, granular fertilizer mixture, internal overburden, microscopy, mineral fertilizer, phosphogypsum, slow release, trace elements, vermiculite, X-ray diffraction

*e-mail: kuzhantasov@rambler.ru 


\section{Introduction}

Enterprises that operate on natural raw materials and generate solid, liquid and gaseous effluents per hour largely encompass the chemical, metallurgical, mining, heat and power enterprises, and more. In total, post-Soviet countries dump more than 80 billion tons of solid waste, including 1.6 billion tons of toxic and carcinogenic contaminants [1]. Such wastes include phosphorous sludge and electrothermophosphoric slag from the electrothermal production of yellow phosphorus [2-5], as well as phosphogypsum, a byproduct from the production of phosphoric acid by treating apatite and phosphorites rocks via the chemical process [6-8].

According to experts, enterprises dump about 140 million tons of phosphogypsum, with an annual increase of 14 million tons. Reprocessing rate of phosphogypsum in Kazakhstan is approximately 2 to $4 \%$ per year, while in Germany, Belgium and Japan, it is almost $100 \%$ [1-4]. Advanced countries (such as the USA, Germany, and Japan) recycle the most phosphogypsum, later used to manufacture cement, paint, and varnishes, and in construction, chemical and agricultural sectors. Due to the climate change [9], the most promising areas for the application of phosphogypsum lie in the field of agriculture (e.g.) reclamation and fertilization. Soil processes can be intensified with a biotechnological approach involving the use of microorganisms to degrade phosphogypsum waste [10].

For 1 ton of extractive phosphoric acid (EPA) produced by reacting sulfuric acid with Karatau phosphorites, about 6 tons of phosphogypsum are generated, the specific surface area of which ranges from 0.15 to $0.24 \mathrm{~mm}^{2}$, with a moisture content of approximately $40 \%[6]$.

The primary phosphogypsum disposal method in Kazakhstan is landfill disposal, which has a negative impact on the environment. In landfills and dumpsites, phosphogypsum is exposed weathering processes, which cause the phosphogypsum to leach harmful substances into the air, soil, groundwater, and surface water. Besides environmental damage, improper phosphogypsum disposal leads to substantial economic losses (transport and storage costs account for up to $10 \%$ of the total cost of the phosphoric acid) [11, 12].

Analysis of the physicochemical properties of phosphogypsum shows that it has an angle of repose around 33 degrees and the bulk density about $1300 \mathrm{~kg} / \mathrm{m}^{3}$. Phosphogypsum generally contains, next to calcium sulphate and water, varying amounts of different compounds, such as $\mathrm{P}_{2} \mathrm{O}_{5 \text { total }}(0.74 \%), \mathrm{N}_{2} \mathrm{O}(0.38 \%)$, $\mathrm{Al}_{2} \mathrm{O}_{3}(0.087), \mathrm{F}(0.081 \%)$, and $\mathrm{Fe}_{2} \mathrm{O}_{3}(0.093 \%)$, as well as insoluble residues (19.67\%) and traces of $\mathrm{MgO}$ [3].

Some authors suggest using neutralized phosphogypsum [5-7], the effect of which lasts 2 years. Sometimes, farmers apply organic-mineral fertilizers, which proceeds the plowing of the land. The mineral component of such fertilizers may be phosphogypsum (20-25 parts by weight), while the organic component can be represented by the lignin sludge ( $75-80$ parts by weight). These fertilizer mixtures enhance the growth of crops and facilitate the uptake of heavy metals and rare earth metals by plants.

When conducting experimental studies on materials collected from dumpsites, one should keep in mind that under certain moisture and temperature conditions, a reaction can take place with inorganic salts and elements in the soil environment. One example is the reaction between monocalcium phosphate and hydrocarbonate, as shown below:

$$
\mathrm{Ca}\left(\mathrm{H}_{2} \mathrm{PO}_{4}\right)_{2}+\mathrm{Ca}\left(\mathrm{HCO}_{3}\right)_{2} \rightarrow \mathrm{Ca}_{3}\left(\mathrm{PO}_{4}\right)_{2}+2 \mathrm{H}_{2} \mathrm{CO}_{3}
$$

In an acidic environment, sparingly soluble salts of phosphoric acid can form, such as during the reaction with iron and aluminum hydroxides:

$$
\begin{aligned}
& \mathrm{Fe}(\mathrm{OH})_{3}+\mathrm{H}_{3} \mathrm{PO}_{4} \rightarrow \mathrm{FePO}_{4}+3 \mathrm{H}_{2} \mathrm{O} \\
& \mathrm{Al}(\mathrm{OH})_{3}+\mathrm{H}_{3} \mathrm{PO}_{4} \rightarrow \mathrm{AlPO}_{4}+3 \mathrm{H}_{2} \mathrm{O}
\end{aligned}
$$

In addition to that, when absorbing any cation from the solution, soil releases an equivalent amount of another cation from the solid phase into that solution (law of conservation of mass). The reaction is as follows:

$$
\begin{aligned}
& \mathrm{Na} \\
& \mathrm{Ca}(\text { soil })+2 \mathrm{NaCl} \rightarrow \text { (soil) }+\mathrm{CaCl}_{2} \\
& \mathrm{Na}
\end{aligned}
$$

The adsorption strength of monovalent cations increases in the following order: $\mathrm{Li}^{+}<\mathrm{Na}^{+}<\mathrm{HN}^{+}<\mathrm{K}^{+}$ $<\mathrm{Rb}^{+}$, and for divalent cations: $\mathrm{Mg}^{2+}<\mathrm{Ca}^{2+}<\mathrm{Co}^{2+}$. In case of trivalent cations, the adsorption strength increases in the following order: $\mathrm{Al}^{3+}<\mathrm{Fe}^{3+}[13]$.

Active acidity is due to the presence of hydrogen ions in the soil solution. The carbon dioxide formed in the soil solution as a result of biological activity has an acidifying effect according to the following equation:

$$
\begin{aligned}
& \mathrm{H}_{2} \mathrm{O}+\mathrm{CO}_{2}=\mathrm{H}_{2} \mathrm{CO}_{3} \\
& \mathrm{H}_{2} \mathrm{CO}_{3}^{-}=\mathrm{H}^{+}+\mathrm{HCO}_{3}
\end{aligned}
$$

The presence of absorbing sodium ions in the soil solution can lead to the formation of sodium bicarbonate or sodium carbonate. The reaction is as follows:

$$
\begin{array}{rc}
\mathrm{Na} & \mathrm{H} \\
(\mathrm{Soil})+\mathrm{H}_{2} \mathrm{CO}_{3} & \rightarrow(\text { Soil })+\mathrm{NaCO}_{3} \\
\mathrm{Na} & \mathrm{H}
\end{array}
$$

In aqueous solutions, carbonic acid salts undergo hydrolytic dissociation, as shown below: 


$$
\begin{aligned}
\mathrm{Ca}\left(\mathrm{HCO}_{3}\right)_{2}+2 \mathrm{H}_{2} \mathrm{O} & =\mathrm{Ca}(\mathrm{OH})_{2}+2 \mathrm{H}_{2} \mathrm{CO}_{3} \\
\mathrm{NaHCO}_{3}+\mathrm{H}_{2} \mathrm{O} & =\mathrm{NaOH}+\mathrm{H}_{2} \mathrm{CO}_{3}
\end{aligned}
$$

Because $\mathrm{NaOH}$ is a strong base, $\mathrm{Ca}(\mathrm{OH})_{2}$ is a moderate base, and $\mathrm{H}_{2} \mathrm{CO}_{3}$ is a weak acid, when carbon dioxide dissolves, the reaction shifts towards an alkaline medium and makes the bases show their properties.

Exchangeable acidity is the amount of hydrogen and aluminum ions that are displaced by the neutral salt when a new complex is added:

$$
\begin{gathered}
(\text { Soil }) \equiv \mathrm{H}+\mathrm{KCl}=(\text { soil }) \equiv \mathrm{K}+\mathrm{HCl} \\
(\text { Soil }) \equiv \mathrm{Al}+3 \mathrm{KCl}=(\text { soil }) \equiv \mathrm{K}+\mathrm{AlCl}_{3} \\
\mathrm{AlCl}_{3}+3 \mathrm{H}_{2} \mathrm{O}=\mathrm{Al}(\mathrm{OH})_{3}+3 \mathrm{HCl}[14-16] .
\end{gathered}
$$

The current paper offers a methodology, which can be useful in creating one-time solutions and temporary manufacturing instructions, justifying the fertilization process parameters, deciding on supplemental technical specifications, and collecting input data for project planning and technical-economic assessment of the production.

\section{Experimental}

All studies took place between 2020 and 2021 at the M. Auezov South Kazakhstan University (Shymkent, Kazakhstan). Phosphogypsum samples for this study were taken from the old ( $>17$ years) and new (approximately 3 years) dumpsites that belong to the Taraz branch of Kazphosphate LLP (Mineral Fertilizers Plant). All representative samples underwent chemical and mineralogical (X-ray diffraction) examinations, thermogravimetry (TG), differential thermal analysis (DTA), Fourier-Transform Infrared (FTIR) spectroscopy, and polarized optical microscopy (POM). The results of these analyses were used to create a new formulation of a fertilizer mixture.

X-ray diffraction (XDM) data were collected by a D8 Advance diffractometer (Bruker) equipped with a $\mathrm{Cu} \mathrm{K \alpha}$ radiation source at $40 \mathrm{kV}$ and $40 \mathrm{~mA}$. From X-ray diffraction patterns, the interplanar distances (d values) were calculated. For this, the EVA software was used. Sample decoding and phase identification were carried out using the search-match software and the PDF-2 database.

The thermal analysis of samples weighted $0.250 \mathrm{~g}$ was performed on a simultaneous thermal analyzer STA 449 F3 Jupiter. Before testing, the furnace chamber was evacuated until the vacuum level reached $92 \%$ and then purged with an inert gas for 5 minutes. The samples were heated at $10^{\circ} \mathrm{C} / \mathrm{min}$ in a highly purified argon atmosphere and then cooled down at $12^{\circ} \mathrm{C} / \mathrm{min}$. The total volume of incoming gas was kept within $100 \mathrm{ml} / \mathrm{min}$. The results were processed using the NETZSCH Proteus software.
The Fourier-Transform Infrared (FTIR) spectroscopy analysis was performed on FT-IR spectrometer Avatar 370 in the spectral range $4000-300 \mathrm{~cm}^{-1}$. For this, $2 \mathrm{mg}$ of phosphogypsum powder was mixed with $200 \mathrm{mg}$ of $\mathrm{KBr}$ and pressed to form a tablet.

The polarized optical microscopy (POM) was performed on a LEICA DM $2500 \mathrm{P}$ microscope. For this, granular phosphogypsum samples from both the old and new dumpsites were placed in an immersion medium of known refractive index. Meanwhile, the artificial polished sections were prepared to determine the presence of ore minerals in the studied samples.

Mineral fertilizers were tested in accordance with ISO 5316-77, ISO 6598-85, ISO 7497-84, the EAEU technical regulation on the Requirements to Mineral Fertilizers (EAEU TR 039/2016), GOST 4212-76 (Reagents. Methods for preparing solutions for colorimetric and nephelometric analysis), ISO 5316-77, ISO 6598-85, ISO 7497-8, and ISO/IEC 17025-2019.

Future research should examine the effectiveness of the new fertilizer mix using agrochemical tests, including the field, growth, lysimetric and laboratory tests. While the field, growth, and lysimetric tests measure the effectiveness of fertilizers, crop nutrient removal, and losses, the laboratory tests refer to the chemical experiment.

\section{Results}

\section{Phosphogypsum Samples from the Old Dumpsite}

The phosphogypsum samples from the old dumpsite were placed in an immersion medium and investigated under a microscope. The results show that these samples had 85 to $90 \%$ of gypsum. It is a monoclinic mineral with indices of refraction $\mathrm{Ng}=1.529$ and $\mathrm{Np}=1.520$, optically positive $(2 \mathrm{~V} \sim 58 \mathrm{o})$. In addition to that, XDM revealed small quantities of quartz and bassanite-like (hemihydrate) phase. The polished section contains copper-bearing minerals: metallic copper, chalcocite, bornite, and pyrite.

\section{Phosphogypsum Samples from the New Dumpsite}

Visually, the light gray powdered sample from the new dumpsite is similar to that from the old dumpsite. Under the microscope, both samples turned out to be identical in terms of composition and XDM data. The ore part of the sample was also similar to that from the old dumpsite. The XDM findings are depicted in Tables 1 and 2 .

The comparison of data in Tables 1 and 2, reveals $1.5-3 \%$ differences in relation to all components. This can be explained by the grinding, which took place in samples from the old dumpsite due to over 40 years of storage.

The thermal analysis of phosphogypsum samples from the old and new dumpsites are depicted in Figs 1 and 2, 
Table 1. The mineralogical composition of phosphogypsum from the new dumpsite.

\begin{tabular}{|c|c|c|c|}
\hline Pattern \# & $\begin{array}{c}\text { Compound } \\
\text { Name }\end{array}$ & Formula & S-Q \\
\hline PDF 36-0432 & Gypsum & $\mathrm{CaSO}_{4} \cdot 2 \mathrm{H}_{2} \mathrm{O}$ & $85.04 \%$ \\
\hline PDF 79-1906 & Quartz & $\mathrm{SiO}_{2}$ & $10.58 \%$ \\
\hline PDF 33-0310 & Bassanite, syn & $\mathrm{CaSO}_{4} \cdot 0.5 \mathrm{H}_{2} \mathrm{O}$ & $4.38 \%$ \\
\hline
\end{tabular}

Table 2. The mineralogical composition of phosphogypsum from the old dumpsite.

\begin{tabular}{|c|c|c|c|}
\hline Pattern \# & $\begin{array}{c}\text { Compound } \\
\text { Name }\end{array}$ & Formula & S-Q \\
\hline PDF 36-0432 & Gypsum & $\mathrm{CaSO}_{4} \cdot 2 \mathrm{H}_{2} \mathrm{O}$ & $87.93 \%$ \\
\hline PDF 79-1906 & Quartz & $\mathrm{SiO}_{2}$ & $9.10 \%$ \\
\hline PDF 00-047-0964 & $\begin{array}{c}\text { Bassanite, } \\
\text { syn }\end{array}$ & $\mathrm{CaSO}_{4} \cdot 0.67 \mathrm{H}_{2} \mathrm{O}$ & $2.97 \%$ \\
\hline
\end{tabular}

respectively. The DTA curve in Fig. 2 (old-dumpsite specimen) clearly exhibits the combination of endothermic and exothermic effects on the DTA curve can be attributed to gypsum $\left(\mathrm{CaSO}_{4} \cdot 2 \mathrm{H}_{2} \mathrm{O}\right)$. The first endothermic effect located at $182.9^{\circ} \mathrm{C}$ indicates dehydration of gypsum to hemihydrate, whereas the second endothermic effect at $214.5^{\circ} \mathrm{C}$ corresponds to the complete dehydration of the phosphogypsum. The exothermic effect at $427.7^{\circ} \mathrm{C}$ can be explained by lattice rearrangement and transformation of di- and hemihydrate gypsum to insoluble anhydrite. The weak minimum at $218.2^{\circ} \mathrm{C}$ on the DTG curve could indicate dehydration of the hydrated silica gel $\left(\mathrm{SiO}_{2} \cdot \mathrm{nH}_{2} \mathrm{O}\right)$. In addition to that, the exothermic effect could be a sign of hydrated silica gel crystallization.

The DTA curve in Fig. 1 (new-dumpsite specimen) also shows the combination of endothermic and exothermic effects on the DTA curve can be attributed to gypsum $\left(\mathrm{CaSO}_{4} \cdot 2 \mathrm{H}_{2} \mathrm{O}\right)$. The first endothermic effect located at $186.4^{\circ} \mathrm{C}$ is due to dehydration to hemihydrate, whereas the second endothermic effect at $216^{\circ} \mathrm{C}$ is due to complete dehydration. The exothermic effect at $458.2^{\circ} \mathrm{C}$ can be explained by lattice rearrangement and transformation of dihydrate gypsum to insoluble anhydrite.

The following findings may be due to the presence of silicic acid $\left(\mathrm{nSiO}_{2} \mathrm{mH}_{2} \mathrm{O}\right)$ : a DTA minimum located at $143^{\circ} \mathrm{C}$ and a weak exothermic effect on the dDTA curve with a peak at $196^{\circ} \mathrm{C}$. First, dehydration took place at $143^{\circ} \mathrm{C}$ with the formation of silica gel, which then crystallized at $196^{\circ} \mathrm{C}$. A weak DTG maximum at $201.7^{\circ} \mathrm{C}$ may be due to oxidation of the ferrous iron. A DTG minimum at $207.7^{\circ} \mathrm{C}$ and a weak exothermic effect on the dDTA curve with a peak at $1009.1^{\circ} \mathrm{C}$ may

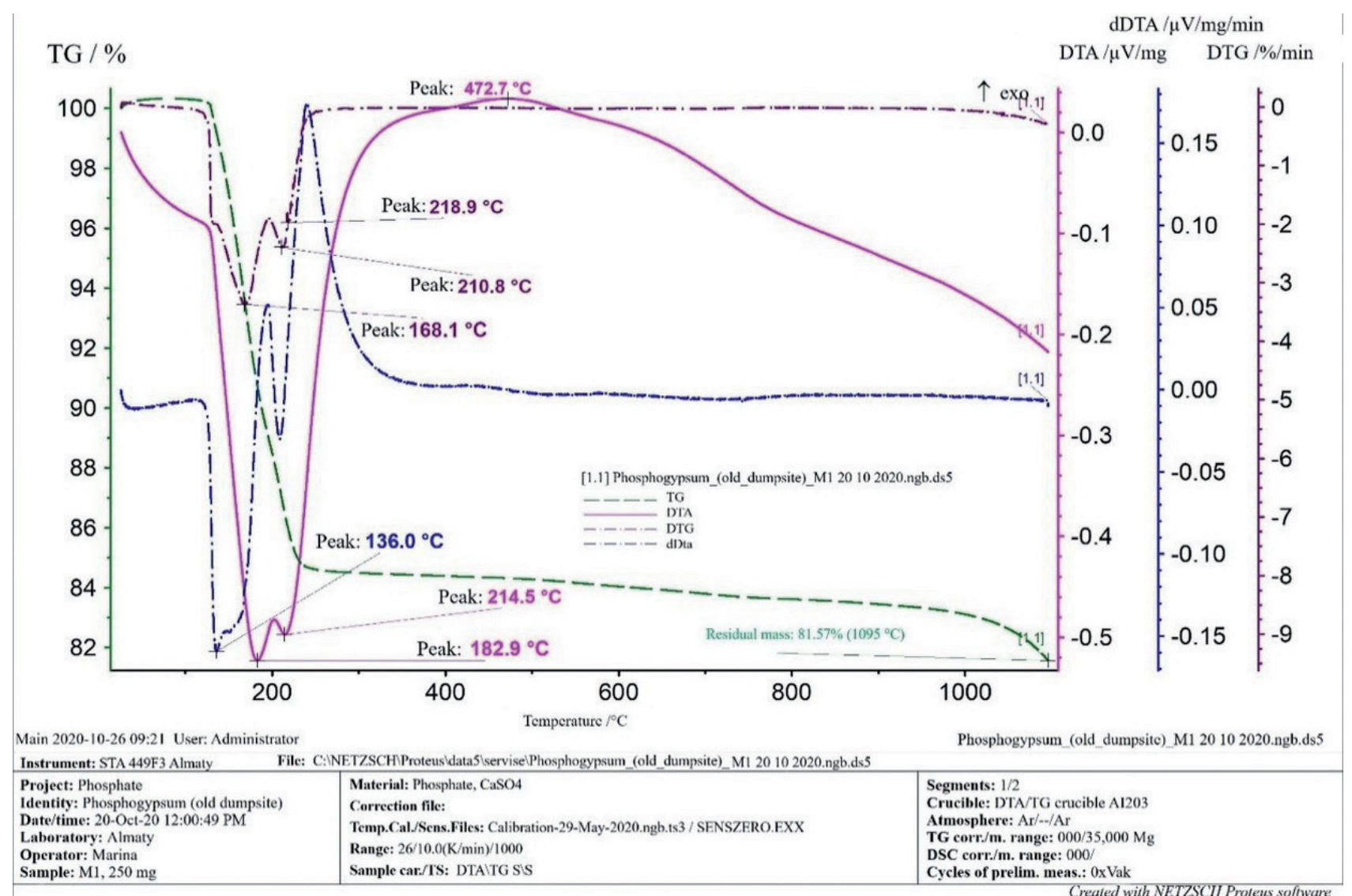

Fig. 1. The thermal analysis of phosphogypsum from the old dumpsite. 


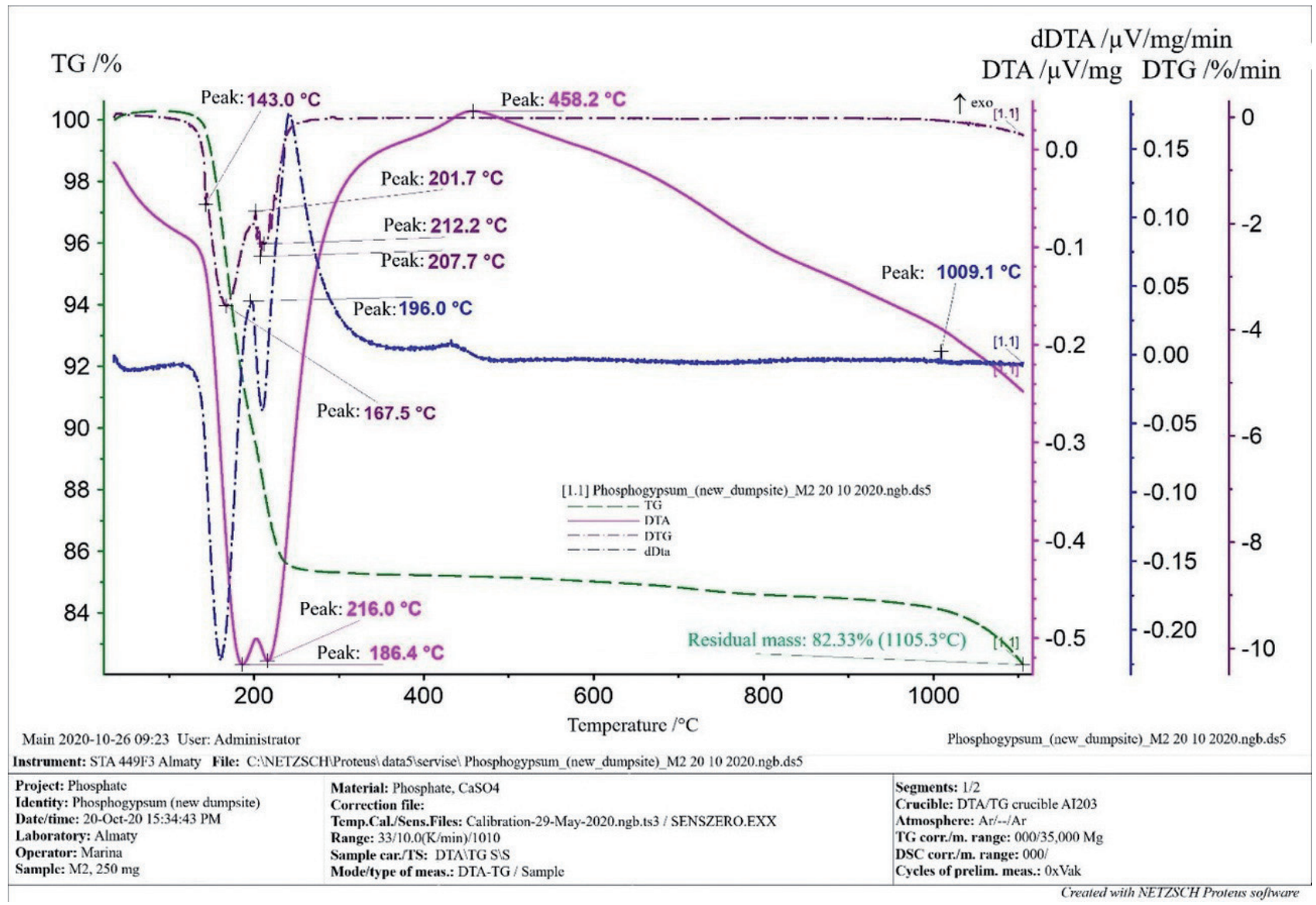

Fig. 2. The thermal analysis of phosphogypsum samples from the new dumpsite.

be associated with the presence of a small amount of aluminum phosphate $\left(\mathrm{Al}_{3}\left[\mathrm{PO}_{4}\right](\mathrm{OH})_{6} 6 \mathrm{H}_{2} \mathrm{O}\right)$. In this case, dehydration may be seen at $207.7^{\circ} \mathrm{C}$ with the formation of an amorphous substance, the presence of which leads to the amorphous phase crystallization at $1009.1^{\circ} \mathrm{C}$.

The FTIR analysis of phosphogypsum samples from the old dumpsite (Fig. 3) indicated the presence of gypsum $\left(\mathrm{CaSO}_{4} \cdot 2 \mathrm{H}_{2} \mathrm{O}\right)$ and quartz $\left(\mathrm{SiO}_{2}\right)$. The welldefined peaks of gypsum can be seen at 3548, 3496, 3404, 3244, 1686, 1621, 1145, 1115, 1004, 669, and

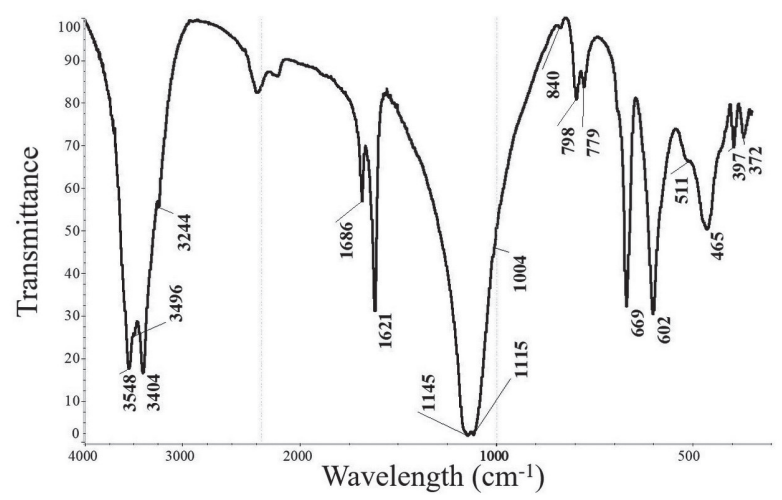

Fig. 3. FTIR spectroscopy results for phosphogypsum from he old dumpsite.
$602 \mathrm{~cm}^{-1}$. The peaks of quartz are located at 798, 779, $511,465,397$, and $372 \mathrm{~cm}^{-1}$.

The FTIR spectrum of phosphogypsum from the new dumpsite (Fig. 4) shows insignificant deviations in relation to peaks depicted in Fig. 4, but the composition of both samples is similar: gypsum $\left(\mathrm{CaSO}_{4} \cdot 2 \mathrm{H}_{2} \mathrm{O}\right)$ and quartz $\left(\mathrm{SiO}_{2}\right)$. This time, the well-defined peaks of gypsum can be seen at 3554, 3494, 3409, 3244, 1684, $1621,1148,1116,1005,669$, and $602 \mathrm{am}^{-1}$. The peaks of quartz are located at 798, 779, 511, 469, 398, and $374 \mathrm{~cm}^{-1}$.

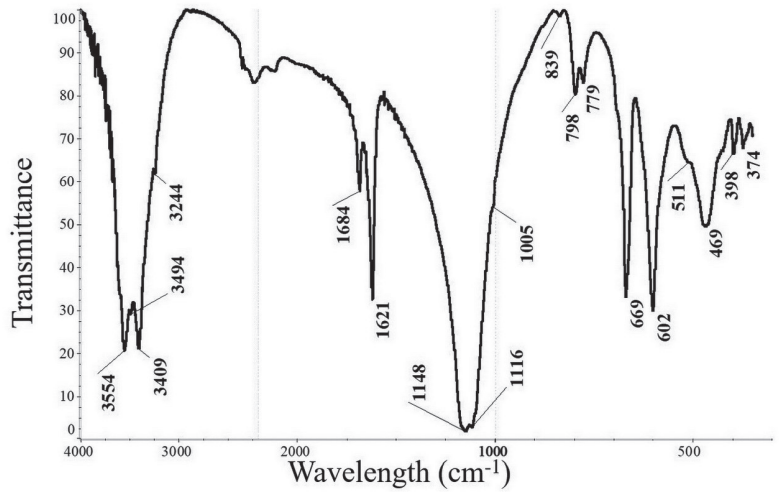

Fig. 4. FTIR spectroscopy results for phosphogypsum from the new dumpsite. 


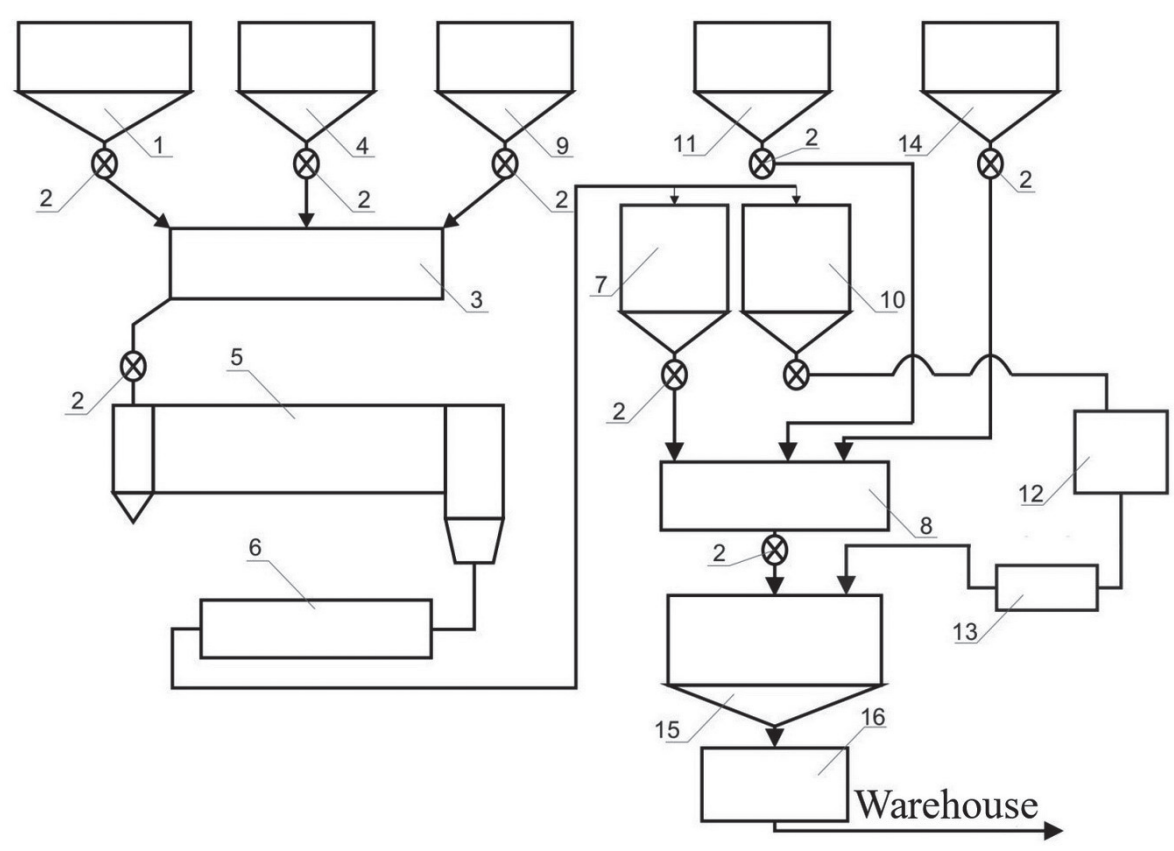

Fig. 5. Manufacturing process of phosphogypsum-containing fertilizer mixtures:

$1,4,7,9,10,11,12,14$, and 15 - bins; 2 - proportioning feeder; 3 and 13 - mixers; 5 - drum furnace; 6 - cooler; 8 - grinding mill; 16 - bagging machine.

\section{Discussion}

Due to moderate solubility of gypsum in water $(2.5 \mathrm{~g} / \mathrm{l})$, some researchers assigned it a modest role in displacing exchangeable sodium [17]. However, when interacting with the alkali soil, it becomes more soluble in water due to the binding of calcium ions, and the increase is substantial. In dynamic conditions when a solution moves through the illuvial zone of the alkali soil due to capillary action, the water solubility of gypsum is somewhat similar to that of phosphogypsum. In stationary conditions, which correspond to the interaction of $\mathrm{Na} / \mathrm{Ca}$ and $\mathrm{Na}$ with clays and loams, the water solubility of gypsum is 1.2-5.7 times higher. Theoretically, the solubility index of gypsum increases if the following conditions are met: increased constants of sodium-calcium exchange, decreased solid-to-liquid ratio, and increased exchange capacity. An increase in the solubility of gypsum in a liquid phase during its interaction with clays is largely associated with a shift in dissolution equilibrium towards new portions. It is apparently due to the absorption of one of the products of the reaction with calcium ions by the absorption complex, as well as ion pair formation.

\section{Technology of Phosphogypsum-Containing Fertilizer Production}

Based on the results of the study above, a production line was designed to produce granular fertilizer mixes with phosphogypsum that would improve the properties of soil. A granular fertilizer flow chart

Table 3. Material balance for complex fertilizer manufacturing process.

\begin{tabular}{|c|c|c|c|c|c|}
\hline \multicolumn{3}{|l|}{ Input quantity } & \multicolumn{3}{|l|}{ Output quantity } \\
\hline Raw material & $\mathrm{kg}$ & $\%$ & Output & $\mathrm{kg}$ & $\%$ \\
\hline $\begin{array}{l}\text { Phosphorite fines from phosphorus production and/or } \\
\text { thermal phosphorite treatment }\end{array}$ & 670 & 67.0 & $\begin{array}{l}\text { Complex-mixed, slow-release mineral } \\
\text { fertilizer mixture }\end{array}$ & 990 & 99.0 \\
\hline Vermiculite & 115 & 11.5 & \multirow{4}{*}{ Mechanical losses } & \multirow{4}{*}{10} & \multirow{4}{*}{1.0} \\
\hline Internal overburden of brown coal & 100 & 10.0 & & & \\
\hline Phosphogypsum & 65 & 6.5 & & & \\
\hline Brown coal & 50 & 5.0 & & & \\
\hline Total & 1000 & 100 & Total & 1000 & 100 \\
\hline
\end{tabular}


captured in Fig. 5 gives details on the production process of granular fertilizer mixtures with phosphogypsum.

To reduce environmental load, as well as fuel and energy costs associated with phosphorite processing, manufacturers may use electrostatic precipitators to trap calcination dust generated at $950-1100^{\circ} \mathrm{C}$ and phosphorite fines from phosphorus production caught in a cyclone during agglomeration. Another alternative is calcined vermiculite, which manufacturers may get from other providers on a contractual basis. To improve the quality of spread of phosphogypsum-containing fertilizer mixtures, manufacturers should use soap stock from alkaline refining as a binder [18].

Based on the material balance calculations, a report was made (Table 3), which showcases the quantities of all materials that will enter and leave the proposed production line.

Under the proposed production model, the manufacturing process of phosphogypsum-containing fertilizer mixtures has four steps:

(1) Phosphorite processing. A proportioning feeder 2 supplies a pre-set quantity of phosphorite fines (size fraction, $0-5 \mathrm{~mm}$ ) from a bin 1 to a mixer 3 , where they are mixed together with tared fines of brown coal, fed from another bin 4. After mixing, the fines enter a rotary drum furnace 5 , in which they undergo drying at a temperature of $150-350^{\circ} \mathrm{C}$ and thermal treatment at $850-950^{\circ} \mathrm{C}$. A calcined product then enters a cooler 6 in which it cools down to $40^{\circ} \mathrm{C}$ before traveling to a collection bin 7 mounted in front of a grinding mill 8 .

(2) Vermiculite processing. Natural vermiculite from a bin 9 and small fines of brown coal (size fraction, $0-5 \mathrm{~mm}$ ) from a bin 4 are mixed together in a mixer 3 . The burden mixture is then fed to a rotary drum furnace 5 for drying and calcination at temperatures of up to $950^{\circ} \mathrm{C}$, and then to a cooler 6 , so that it cools down do $40^{\circ} \mathrm{C}$. A cooled product is transported to a separate bin 10 .

(3) Grinding and mixing of individually prepared components. The calcined phosphorite from a collection bin 7 and internal overburden fines (size fraction, 0-5 $\mathrm{mm}$ ) from a bin 11 are sent to a centrifugalelliptical ball mill for grinding until a fraction of less than $0.1 \mathrm{~mm}$. After grinding, the product enters an intermediate bin 12 where it waits to be sent to a mixer 13. The phosphorite-based granules are mixed with phosphogypsum from a bin 14 and calcined vermiculite from a bin 10. Once mixed, the product is sent to a final bin 15 where it is kept before transportation to a bagging machine 16 .

(4) Bagging. The fertilizer mixture is bagged and sent to a warehouse for storage.

\section{Conclusions}

This study examined phosphogypsum specimens from the old and new dumpsites. No significant differences were found in the chemical and mineralogical composition between them. According to the results of the XDM mineralogical analysis, both phosphogypsum samples contain gypsum (87.93\% vs $85.04 \%$, respectively), quartz $(9.10 \%$ vs $10.58 \%$, respectively); basanite ( $2.97 \%$ vs $4.38 \%$, respectively). The TG/DTA analysis indicated the presence of insignificant temperature peaks. This finding coincides with the results of the FTIR spectroscopy. The current paper also offers a technological scheme for making a slow-release fertilizer mixture containing a phosphate substance, vermiculite as a water-retaining component, internal overburden with trace elements, and phosphogypsum as a neutralizer to reduce soil acidity and salinity.

\section{Conflict of Interest}

The authors declare no conflict of interest.

\section{References}

1. ILYIN A.P. Modern Problems of Inorganic Chemical Engineering; Ivanovo State University of Chemical Technology: Ivanovo, 2011.

2. ZHANTASOV K.T., SHAPALOV S.S., BERZHANOVA D.S., KADIRBAYEVA A.A., ZHANTASOVA D.M., ALTEEV T., MIRZAEV A.A. Production of Glyphosate Using Waste From Phosphorus Production and Organic Compounds. M. Auezov South Kazakhstan State University: Shymkent, 2018.

3. ERSHOV V.A. The problem of comprehensive Karatau phosphorite processing. Fosfornaya promyshlennost [Phosphorus production], 3 (8), 16, 1972.

4. ZHANTASOV K.T., AIBALAEVA K.D., FRANGULIDI L.K., BARLYBAEV M.R., BERZHANOV D.S., YURCHENKO B.N., ZHANTAOSV M.K. Technological equipment for yellow phosphorus production (textbook). International Journal of Applied and Fundamental Research, 3 (2), 199, 2014.

5. VANDEN NEST T., RUYSSCHAERT G., VANDECASTEELE B., COUGNON M., MERCKX R., REHEUL D. P availability and P leaching after reducing the mineral $\mathrm{P}$ fertilization and the use of digestate products as new organic fertilizers in a 4-year field trial with high $\mathrm{P}$ status. Agriculture, Ecosystems \& Environment, 202, 56, 2015.

6. CHAUDHARY S., DHERI G.S., BRAR B.S. Long-term effects of NPK fertilizers and organic manures on carbon stabilization and management index under rice-wheat cropping system. Soil and Tillage Research, 166, 59, 2017.

7. ZHANTASOV K.T., ISKANDIROV M.Z., AIBALAEVA K.D., ALTEEV T.A., NOVIK D.M., ZHANTASOVA, D.M. Modern Technologies for Processing Mineral Raw Materials: A Textbook; M. Auezov South Kazakhstan State University: Shymkent, 2015.

8. CHERNYSH Y., YAKHNENKO O., CHUBUR V., ROUBÍK H. Phosphogypsum recycling: A review of environmental issues, current trends, and prospects. Applied Sciences, 11 (4), 1575, 2021.

9. TRIFI H., NAJJARI A., ACHOUAK W., BARAKAT M., GHEDIRA K., MRAD F., SAIDI M., SGHAIER H. 
Metataxonomics of Tunisian phosphogypsum based on five bioinformatics pipelines: Insights for bioremediation. Genomics, 112 (1), 981, 2020.

10. BELYUCHENKO I.S. RF Patent No. 2423812. Method to Improve the Agrophysical Properties of Soil (A01B7 9/02, 2011), 2011.

11. IVANITSKIY V.V., KLASSEN P.V., NOVIKOV A.A., STONIS S.N., EVENCHIK S.D., YAKOVLEVA M.E. Phosphogypsum and Its Use; Khimiya: Moscow, 1990.

12. YANG R., SU Y., WANG T., YANG Q. Effect of chemical and organic fertilization on soil carbon and nitrogen accumulation in a newly cultivated farmland. Journal of Integrative Agriculture, 15 (3), 658, 2016.

13. TANIRBERGENOV S., SAPAROV A., SULEYMENOV B. Methods of increasing productivity and environmental sustainability of cotton on irrigated light gray soils of the South Kazakhstan region. In International Congress on "Soil Science in International Year of Soils"; Sochi, Russia, 405, 2015.
14. FARAHANI S.S., RAJABIPOUR A., KEYHANI A., SHARIFI M. Energy use and economic analysis of NPK15: 8: 15 fertilizer granulation process in Iran. Journal of the Saudi Society of Agricultural Sciences, 16 (3), 265, 2017.

15. CAMERON K.C., DI H.J., MOIR J.L. Nitrogen losses from the soil/plant system: a review. Annals of Applied Biology, 162 (2), 145, 2013.

16. BAZHIROVA K.N. Development of an Energy-Saving Technology for the Production of Mechanically Activated, Slow-Release Mineral Fertilizers; Shymkent, 2015.

17. ZHANTASOV K.T., BAZHIROV N. S., BISHIMBAEV V.K., BAZHIROV T.S., ZHANTASOV M.K., BAZHIROVA K.N., OMAROV B.T., NALIBAEV M.I. Patent RK No. 31226. Method to Grind PhosphorusContaining Materials. Decision on Patent Under Application No. 2013/1487.1, dated July 28, 2014, 2014. 